\title{
Design of 3D Printer and Development of Its Control System
} \author{
Jiabing $\mathrm{Hu}^{1, \mathrm{a}^{*}}$ and $\mathrm{HaO} \mathrm{Wu}^{2, \mathrm{~b}}$ \\ ${ }^{1}$.Key Laboratory of Metallurgical Equipment and Control Technology, Ministry of Education, \\ Wuhan University of Science and Technology, Wuhan 430081, China; \\ 2.Hubei Key Laboratory of Mechanical Transmission and Manufacturing Engineering, \\ Wuhan University of Science and Technology, Wuhan 430081, China; \\ a461303771@qq.com, ${ }^{b} 1252334436 @ q q . c o m$ \\ * the corresponding author
}

Keyword: 3D printer design; Control system development; Mach3 dashboard; Frame design

\begin{abstract}
Accompanied by the progress of the times and the development of social science and technology, the scale of manufacturing design and processing has been developing rapidly. 3D printing technology has been practically used in all walks of life. 3D printing technology is characterized by its strong simulation, high efficiency, low cost and easy operation, which give people a great convenience. In this paper, the overall development trend of 3D printing technology is taken as an entry point. Based on the Mach3 control board, the author designs and analyzes the frame structure of 3D printer, the transmission part of 3D printer and the part of the control board of the 3D printer. The main control board of the control system is described and the working principle of the Mach3 host platform is described in detail. At the same time, by analyzing some problems occurred in the design process, and put forward a reasonable solution to the problem.
\end{abstract}

\section{Introduction}

Accompanied by the progress of the times and the development of social science and technology, the scale of manufacturing design and processing has been developing rapidly and the market competition is getting bigger and bigger. 3D printers have become the absolute advantage of the manufacturing industry. Some major technologies such as computer technology (CAD, concurrent engineering) The emergence of the product design and development brought inconvenient convenience [1]. At present, the domestic 3D printing technology is still being explored and initially applied. It takes longer time to achieve a qualitative leap forward, the printing of aircraft titanium alloy components, the printing technology based on the powder bed SLS technology, and the 3D printing of heavy metals. The new era of industry, symbolizing the development of China's 3D printing technology has unlimited room for innovation [2]. At the same time, inkjet printing, developed jointly by the United States and Japan, made a big leap forward in 3D printing, a technology that prints out colored originals. Foreign major companies employ experts to carry out research and development, making inkjet printing can be combined with the camera system, vivid images dazzling color. Foreign technology in the application of the industry developed very rapidly to achieve the human skeleton manufacturing and regeneration, the use of 3D printing technology to create the skeleton can help the damaged parts of the new cell tissue structure, promote blood circulation, can help people with disabilities repair The body makes a great contribution to medicine[3,4].

\section{D Printing Technology and 3D Printer Working Principle}

Existing Common 3D Printing Technology. Existing common 3D printing technologies include SLA, SLS, LOM and FDM [5]. SLA (stereolithography) SLA technology has the longest development history, the most mature technology, the most widely used, high precision, faster forming speed and stable system, but needs to design and support the structure. The support 
structure needs to be removed without complete cure, easily damaging the molded parts. As the material is resin, the temperature is easy to melt, easy to crack. SLS technology has been widely used because of its simple manufacturing process, high material utilization rate, small deformation and so on. LOM (layered entity manufacturing method) LOM technology has the advantages of simple process, high efficiency, high loss and high precision, high precision parts requirements. FDM technology, also known as melt deposition technology. FDM technology is the advantage of a variety of materials can be used to create simple, easy to build hollow workpiece, small pollution. However, the use of this technology makes the overall temperature greatly affected, the effect of the finished product does not reach the expected steady state, so the precision of the finished product, generally do not use this technology [6].

Mach3 Dashboard Introduction. Hardware Platforms Mach3 Platforms: Mach3 is a numerical control hardware platform developed and researched by American companies that must run under Windows XP and Windows 2000. Mach3 software uses USB ports as input and output devices. In order to achieve good control of CNC machine tools, the software supports a variety of international standard $\mathrm{G}$ code. Up to 6 axes can be controlled. High-precision machining of complex parts is possible. With a maximum of $0.0001 \mathrm{~mm}$ of control accuracy and complex functional requirements, the MODBUS unit can be used to control the control of magazines, grippers and debris carriers. A simple system with parallel ports can be implemented [7]. The Mach3 CNC control software is an open CNC system, easy to operate, easy to maintain, stable performance. It is low cost of new CNC system.

The 3D Printer Principle of Control Panel Based Mach3. The whole system of 3D printer is composed of control module, mechanical module, computer technology, printhead consumables and other frame structure. It is mainly divided into three modules: control module, motion module and printing module. The most basic condition for a 3D printer to make 3D parts The printhead and the platform work together on three planes $x-y-z[8,9]$. XY axis composed of plane movement, in which $\mathrm{x}$-axis motor through the non-standard parts installed in the optical axis of the slider, $\mathrm{y}$-axis motor mounted on the frame; motor driven synchronous belt rotation, in order to achieve a planar xy print, $\mathrm{Z}$ axis controlled by the servo motor up and down Exercise, to achieve a hierarchical print driver [10]. During printing, the upper computer software first reads the $\mathrm{G}$ code generated by Cura software based on the three-dimensional digital model (STL), and then transfers the G code to the X3G file and transmits it through serial communication or offline (using USB) The lower Mach3 control platform, at the same time that Mach3 control platform feedback position coordinate information. Hardware system consists of mach3 control panel, heater, sensor, motor and print head. Mach3 hardware controller according to the coordinates of the code location and set the temperature and other information, control the temperature of the workbench and print head temperature, fan of heating device. Then the information is fed back to the upper position real-time[11].

\section{Integral Design of 3D Printer}

3D Printer Drive Part of the Design. Currently on the market, the common 3D printer has the following structure: triangular 3D printer structure, rectangular rod 3D printing structure, but taking into account the consumables, simplicity, accuracy requirements[12]. The selected structure to ensure that less expensive low-cost and relatively high accuracy. Triangular structure is characterized by the triangular structure of the triangular structure of the printer, its bottom is used to place the hot bed where the $\mathrm{X}$-axis is followed by $\mathrm{Z}$-axis components to drive the print head to achieve movement in the plane, the Z-axis is generally in the triangle Of the center line of the part of its XYZ axis of motion do not interfere with each other, making the rack stress distribution is not easy to crooked. Therefore, from the frame point of view on the structural design of choice triangle rod is a good choice. The driving part of the 3D printer mainly has the movement in the $\mathrm{XZ}$ direction of the printing head, the movement in the Y direction of the working platform, and the movement in the XY direction firstly needs to be mounted on the machine frame with the light rod connected between the bearing seats, and the straight line Bearing, due to the design of the printing range of $200 \mathrm{~mm} \cdot 200 \mathrm{~mm} \cdot 220 \mathrm{~mm}$ so choose the optical axis diameter of $8 \mathrm{~mm}$, the base with 
$300 \mathrm{~mm} \cdot 300 \mathrm{~mm}$ aluminum with a high degree of aluminum with $400 \mathrm{~mm}$ angle code will be connected together, which is connected to non-standard parts Driven by the print head to do the optical axis in the $X$ direction using $300 \mathrm{~mm}$ to cut, cut into $100 \mathrm{~mm}$ length, so it will not affect the print travel.

Of course, the transmission part of the design of the non-standard parts of the design, the optical axis of the timing belt pulley and the need for non-standard parts between the fastening to drive the $\mathrm{X}$-axis movement, the design of the drawings shown in Fig. 1and Fig.2:

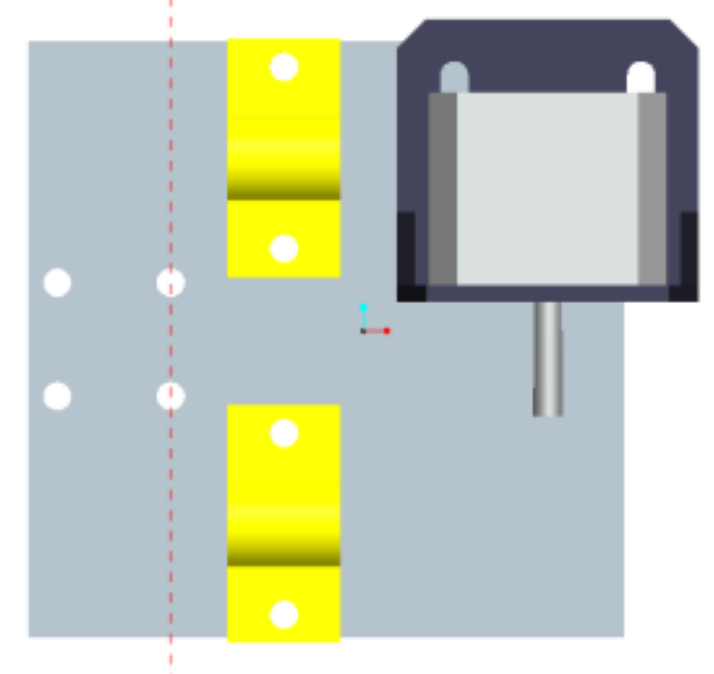

Figure 1. $\mathrm{X}$-axis connection diagram
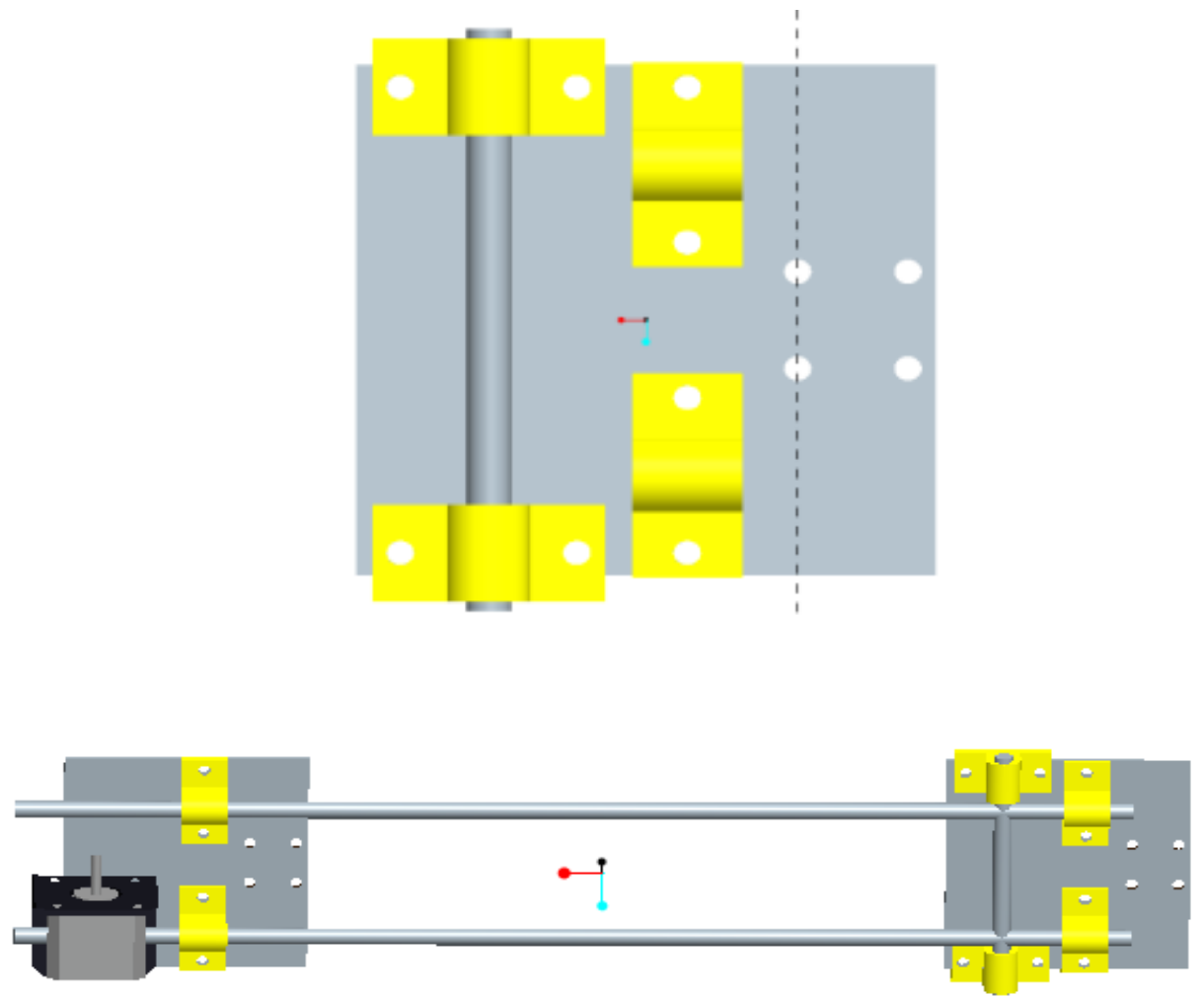

Figure 2. non-standard design connection diagram

Install the timing belt pulley on the $100 \mathrm{~mm}$ optical axis, and then make it parallel with the motor on the upper timing belt, so that the printing head can drive the $\mathrm{X}$-axis direction by the motor. Y-axis motion consists of two optical axes and a screw to complete the work platform through the 
optical axis and the screw base and the bottom of the optical axis and screw fixed, the motor with two 70mm long aluminum with the motor block connection fixed, And then connect the screw and screw, in order to achieve the work platform in the Y-axis movement. Z direction using two motors, the motor is respectively connected with a screw rod, the movement needs screw and screw nut, the screw can not rotate at high speed, high precision, simple structure, but also has a good carrying capacity, transmission efficiency, the most important is With self-locking, these advantages allow us to give priority to the use of screw and screw nut.

Table 1 Screw parameter diagram [mm]

\begin{tabular}{ccccc}
\hline Project & Screw diameter & Pitch & Lead & length \\
\hline T-8 screw & 8 & 2 & 8 & 300 \\
\hline
\end{tabular}

3D Printer Control Board Part of the Design. The board kit includes Mach3 interface board, TB6600 42-step stepper motor driver, cnc interface board, other accessories include: $12 \mathrm{~V}$ power supply, hot bed, 42 stepper motor, REX-C100 thermostat, thermocouple temperature sensor, printer extension cable Line), USB male to male line.

Which Mach3 interface board connected to four motor drives to control the motor rotation, in order to achieve XYZ axis movement and the print head part of the wire extrusion. Second, P12, $\mathrm{P} 13$, P15, respectively, then the $\mathrm{X}, \mathrm{Y}, \mathrm{Z}$ limit switches to limit the maximum and minimum three-axis position. Parallel port connected to the computer similar groove type, arrow direction refers to the flow of information in the computer. In order to achieve the control of the motherboard, you need to install Mach3 software to drive, so that the normal operation of the motor.

\section{Optimization Analysis}

Wire Feeding Agencies. The wire feeding mechanism for 3D printer includes motor, gear, pipes, thermocouple, nozzle and inlet gear. There is a gear in the material inlet. The plastic wire is driven by the gear and passes through the tube to the nozzle. The thermocouple outside the nozzle heats the plastic wire, and the raw material is heated to a molten state and then extruded and printed layer by layer until the physical body, plastic wire in the gear drive, through the catheter to the nozzle, wherein the nozzle external thermocouple for heating plastic wire, the raw material is heated into molten state after extrusion layer printing. Until that entity. The feeding device design and material feeding speed and extrusion speed, which will also 3D machining precision and quality influence, such as feeding device for a long time the work of print abrasion phenomena caused by wire is slow, uneven, slipping problem. So in order to maintain appropriate temperature of spring pressure and nozzle plate stability at design time, both to ensure the printing precision and the work intensity, but also avoid the resulting material return is stuck to the expansion lead material after heating.

Transmission Mechanism. Transmission mechanism mainly by the XYZ movement system, in which the print head in the two motor driven by the synchronous pulley, polished rod, timing belt to achieve $\mathrm{XZ}$ direction of movement, $\mathrm{Z}$ axis positioning accuracy of layered printing accuracy, in order to make the structure Simple, improve the printing accuracy, transmission efficiency, the $\mathrm{Z}$ axis using screw, when driving the motor drive screw clockwise or counterclockwise rotation, through the thread bite, the work platform will be up and down along the $\mathrm{Z}$ axis to achieve hierarchical printing.

Working Platform. 3D printer work platform with fine-tuning the level of structure, in the work of four feet next to the bench with a spring trimmer screw (you can achieve leveling) This will not only prevent the print head and print platform contact too tight, resulting in a huge friction and Print head itself caused damage, but also to prevent the print head from too far away from the platform in order to melt the material can not be glued to the surface, so that print failure (work platform aluminum thickness $2 \mathrm{~mm}$, it is easy to cut the desired shape, easy Punch, and reduce the overall weight). Here hot bed is designed to reduce the overall weight, and force evenly, will not affect the printing. Desktop 3D printer model has a hot bed in the middle of the platform. Due to its high working temperature, it uses a piece of metallic aluminum material and uses anodic oxidation 
process. The surface is very smooth and has good thermal conductivity, allowing the working platform to maintain a certain range of temperature, Extruded silk by the temperature difference, reduce product size error.

\section{Conclusions}

This paper mainly designs and assembles the printer based on Mach3, and completes the structure design and circuit design of the simple desktop 3D printing. Through the analysis of the current situation of the development of 3D printing technology at home and abroad, compared to the existence of the technology gap, Based on the Mach3 control board, the author designs and analyzes the frame structure of 3D printer, the transmission part of 3D printer and the part of the control board of the 3D printer. At the same time, this paper makes a primary analysis on the frame and transmission part of 3D printer, summarizes some problems existing in the design of 3D printer, and puts forward a reasonable solution.

\section{References}

[1] Q. Li and Q. Wang: Distance Education Journal, Vol. 31 (2013) No.4, p.29.

[2] Y.Y. Liu, F.H. Zhang, W.H. Chen, F.F. Yan, L.L. Zheng and Q.X. Hu: Journal of Mechanical Engineering, Vol. 50 (2014) No.15, p. 147.

[3] X. Liu, X. Yu and B. Zhang: Journal of Intelligence, Vol. 34 (2015) No.5, p.41.

[4] F.F. Wu , G.H. Duan and L.C. Huang: Journal of Intelligence, Vol. 32 (2013) No.8, p.62.

[5] J. Zhao, X.H. YU, T.H. Yang, G.Y. Zhou, H. Ling and X. Qiang: Mechanical \& Electrical Engineering Magazine, Vol. 34 (2017) No.5, p.547.

[6] W. Li, C.Y. Wang, Z.G. Wu, H.X. Sun and X.L. Li: Mechanical Engineering \& Automation, (2016) No.1, p.110.

[7] D.X. Zeng, X. Zhang, M.Z. Fan, X.F. Li and Y.1. Hou: China Mechanical Engineering, Vol. 28 (2017) No.12, p.1413.

[8] J. Xu and T.L. Wang: Computer Measurement \& Control, Vol. 25 (2017) No.3, p.51.

[9] X. Li, H. Mo, S.S. Li and F. Y. Wang: Acta Automatica Sinica, Vol. 42 (2016) No.7, p.983.

[10]Z.Y. Deng, J. Zhang, Y.B. Liu and J.R. Xiao: China Machine Engineering, Vol. 16 (2015) No.6, p.766.

[11]Prévost R,Whiting E,Lefebvre S,et al.Make it stand:Balancing shapes for 3D fabrication[J].ACM Trans on Graphics,2013,32(4):81:1-81:10

[12]Q. Ge and Y. Wang. Modern Electronics Technique, Vol.39 (2016) No.22, p.100. 